\begin{tabular}{|c|c|}
\hline & $\begin{array}{r}\text { ABSYARA: Jurnal Pengabdian Pada Masyarakat } \\
\text { Vol. 2, No. 1, Juli } 2021 \\
\text { Hal. } 8-14\end{array}$ \\
\hline 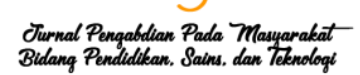 & e-ISSN: $2723-6269$ \\
\hline
\end{tabular}

\title{
Penguatan Konsep Matematis Bagi Guru Matematika Melalui Pelatihan Software Scilab Secara Daring
}

\author{
Syamsuri*1, Hepsi Nindiasari ${ }^{2}$ \\ syamsuri@untirta.ac.id ${ }^{* 1}$ \\ 1,2Program Studi Magister Pendidikan Matematika, Universitas Sultan Ageng Tirtayasa
}

\author{
Received: 22 Februari 2021 \\ Accepted: 23 Juni 2021 Online Published: 31 Juli 2021 \\ DOI: 10.29408/ab.v2i1.3190 \\ URL: http://dx.doi.org/10.29408/ab.v2i1.3190
}

\begin{abstract}
Abstrak: Salah satu kompetensi bagi guru matematika yang pelu dikuasai ialah pendalaman terhadap materi pelajaran berupa konsep-konsep matematis. Diantara metode yang bisa dilakukan ialah melalui pelatihan perangkat lunak pendukung pelajaran matematika. Salah satu perangkat lunak yang bisa digunakan pada pembelajaran matematika adalah perangkat lunak Scilab. Pemanfaatan perangkat lunak Scilab dalam pembelajaran matematika tentunya tidak terlepas dari peran guru. Kegiatan pengabdian ini bertujuan untuk melaksanakan pelatihan daring perangka lunak Scilab untuk pembelajaran matematika. Metode yang digunakan yaitu pelatihan daring, dan evaluasi kegiatan dilakukan dengan cara pengisian kuesioner tentang pengetahuan dan keterampilan dalam menggunakan perangkat lunak Scilab. Pelatihan daring ini dilakukan secara sinkron sebanyak 2 kali pada periode September 2020, dan didampingi secara asinkron melalui aplikasi Edmodo. Guru yang berpartisipasi aktif dalam pelatihan daring ini ada sekitar 68 guru yang tergabung dalam Musyawarah Guru Mata Pelajaran (MGMP) Matematika SMA Kabupaten Lebak dan Matematika Nusantara Wilayah Banten. Respon guru terhadap pembelajaran dengan memanfaatkan perangkat lunak Scilab bergantung pada kemampuan awal guru mengenai perangkat lunak tersebut. Hasil dari kegiatan ini yaitu pelatihan daring ini mampu menambah wawasan guru tentang perangkat lunak pembelajaran matematika khususnya Scilab. Dari 68 peserta yang ikut pelatihan, hanya 36 peserta yang mengisi kuesioner dengan hasil sangat baik sebanyak 8 orang, memuaskan 9 orang, luar biasa 6 orang, cukup 10 orang, dan rendah 3 orang.
\end{abstract}

Kata Kunci: Guru Matematika; Pelatihan Daring; Pembelajaran Matematika; Scilab

\begin{abstract}
One of the competencies mathematics teachers need is the deepening of subject matter in mathematical concepts. Among the methods that can be done is through software training to support mathematics lessons. One of the software that can be used in learning mathematics is Scilab software. The use of Scilab software in mathematics learning cannot be separated from the role of the teacher. This service activity aims to carry out online training for Scilab software for learning mathematics. The method used is an online training and evaluation of activities by a questionnaire about knowledge and skills using Scilab software. This online training was carried out synchronously two times in the September 2020 period and was accompanied asynchronously through the Edmodo software. 68 teachers actively participate in this online training who are members of the Mathematics Subject Teachers' Consultation (MGMP) for Lebak Regency High School Mathematics and Nusantara Mathematics for Banten Region. The teacher's response to learning using the Scilab software depends on the teacher's initial ability to use the software. The result of this activity is that this online training can add insight to teachers about mathematics learning software, especially Scilab. Of the 68 participants who participated in the training, only 36 participants filled out the questionnaire. There is 8 person with excellent results, 9 people satisfied, 6 people extraordinary, 10 people enough, and 3 people low.
\end{abstract}

Keyword: Online Training; Mathematics Learning; Mathematics Teacher; Scilab 
Syamsuri, \& Nindiasari H. (2021). Penguatan konsep matematis bagi guru matematika melalui pelatihan software Scilab secara daring. ABSYARA: Jurnal Pengabdian Pada Masyarakat, 2(1), 8-14. doi:10.29408/ab.v2i1.3190

\section{PENDAHULUAN}

Berdasarkan Permendiknas Nomor 16 Tahun 2007 tentang Standar Kualifikasi Akademik dan Kompetensi Guru, sebagai tenaga pendidik guru harus memiliki empat kompetensi, yaitu; kompetensi pedagogik, kompetensi kepribadian, kompetensi sosial, kompetensi professional (Mendiknas, 2007). Seorang pendidik dituntut agar dapat mewujudkan kinerjanya secara tepat dan efektif (Sutisna, dkk., 2020). Kompetensi profesional bagi guru matematika meliputi penguasaan guru terhadap materi pelajaran berupa konsep-konsep matematis (Dirgantoro, 2018). Penguasaan guru matematis terhadap konsep matematis ini sangat penting agar tujuan pembelajaran bisa dicapai dengan baik. Selain itu, dalam kompetensi pedagogik disebutkan salah satunya adalah memanfaatkan teknologi informasi dan komunikasi untuk kepentingan pembelajaran (Mendiknas, 2007). Demikian halnya dalam kompetensi professional disebutkan bahwa guru harus memanfaatkan teknologi informasi dan komunikasi untuk mengembangkan diri. Dengan demikian, seorang guru harus mampu memanfaatkan teknologi informasi dan komunikasi untuk kepentingan pembelajaran sekaligus mengembangkan diri.

Berdasarkan pengamatan, sebagian besar guru matematika tidak menggunakan media komputer dalam pembelajaran matematika. Pembelajaran matematika biasa dilakukan secara tradisional yaitu menggunakan papan tulis dan spidol. Beberapa guru yang mempunyai laptop atau di sekolahnya memiliki perangkat komputer/laptop dan LCD memanfaatkan peralatan tersebut namun hanya menggunakan microsoft powerpoint. Hal ini kurang memadai untuk pembelajaran matematika. Untuk memanfaatkan komputer dan internet dalam pembelajaran matematika guru harus meningkatkan literasi computer (Ravendran \& Daud, 2020). Literasi komputer merupakan istilah yang sering digunakan untuk menjelaskan pengetahuan dasar yang perlu diketahui orang awam mengenai komputer. Konsep literasi komputer lebih berkaitan dengan segi praktis penggunaan komputer, bukan perancangan dan pengembangan komputer itu sendiri. Literasi komputer yang baik akan mengakibatkan keinginan untuk mempelajari lebih lanjut pemanfaatan komputer oleh guru dalam pembelajaran (Nasution, 2018).

Pemanfaatan komputer sebagai alat bantu belajar atau media pembelajaran sangat luas. Padmanthara (2012) menyebutkan manfaat media komputer untuk pembelajaran, yaitu : Computer-Aided Instruction (CAI), Computer-Based Learning (CBL), Computer-Based Instructrion (CBI), dan Computer-Managed Instruction (CMI). Di antara jenis pemanfaatan tersebut, CAI adalah paling mudah karena hanya memanfaatkan software yang sudah siap pakai. Pada soal-soal matematika yang tinggkat kesulitannya tinggi, penggunaan software terbukti dapat membantu menyelesaikan soal-soal tersebut (Sugilar, 2020). Salah satu software matematika ialah Scilab. Software Scilab merupakan open-source yang bisa dimanfaatkan oleh masyarakat luas. Scilab biasanya digunakan dalam pemodelan matematika di bidang teknik rekayasa, namun Scilab juga bisa digunakan dalam pembelajaran. Randjawali \& Riupassa (2019) menggunakan Scilab dalam penerapan kalkulus di perguruan tinggi. Adapun Supriyadi (2020) menyimpulkan bahwa Scilab bisa digunakan untuk mengukur pemahaman siswa SMK dalam operasi matematika dasar dan dasa-dasar pemrograman komputer. Hal tersebut tentunya mengindikasikan bahwa Scilab layak digunakan bagi guru-guru matematika untuk mengetahui aplikasi dari konsep matematika yang dipelajari di sekolah. Oleh karena itu, diperlukan adanya sutu pelatihan Scilab bagi guru-guru matematika dalam memahami suatu konsep matematis. 
Syamsuri, \& Nindiasari H. (2021). Penguatan konsep matematis bagi guru matematika melalui pelatihan software Scilab secara daring. ABSYARA: Jurnal Pengabdian Pada Masyarakat, 2(1), 8-14. doi:10.29408/ab.v2i1.3190

Di Indonesia, pemanfaatan Scilab masih masih jarang untuk pembelajaran matematika. Kemampuan yang meningkat dari siswa dan kesulitan siswa dalam mengoperasikan software matematika telah banyak diungkap. Padahal keberhasilan pemanfaatan software ini juga bergantung pada guru sebagai fasilitator pembelajaran di kelas. Oleh karena itu, kegiatan pengabdian ini bertujuan untuk melatih guru matematika secara daring agar kemampuan menggunakan software matematika bisa meningkat.

\section{METODE PELAKSANAAN}

\section{Waktu dan Lokasi}

Pelatihan software ini dilaksanakan secara daring pada tanggal 5 dan 19 September 2020. Pelatihan tentang pemanfaatan software pembelajaran matematika, khususnya Scilab kepada guru-guru yang tergabung dalam wadah Musyawarah Guru Mata Pelajaran (MGMP) Matematika SMA Kabupaten Lebak dan Matematika Nusantara Wilayah Banten. Musyawarah Guru Mata Pelajaran adalah forum/wadah kegiatan profesional guru mata pelajaran pada SMP/MTs, SMPLB/MTsLB, SMA/MA, SMK/MAK, SMALB/MALB yang berada pada satu wilayah/kabupaten/kota/ kecamatan/sanggar/gugus sekolah. Pertemuan di MGMP diharapkan memberikan suatu kesempatan yang tepat bagi guru untuk meningkatkan profesionalismenya melalui pelatihan, penulisan karya ilmiah, Dengan demikian MGMP memiliki peran penting dalam mendukung pengembangan profesional guru

\section{Prosedur pelaksanaan}

Pelatihan dilakukan secara synchronous melalui Google Meet selama sekitar 2-3 jam pada hari pertama. Setelah itu, pembelajaran dilakukan secara asynchronous menggunakan aplikasi Edmodo. Guru-guru yang mengikuti pelatihan secara aktif masing-masing 68 guru matematika. Guru-guru diberikan tugas yang bisa dikumpulkan dalam asynchronous. Selain itu, diberikan pula kuesioner pada pertemuan akhir sebagai evaluasi untuk mengetahui keefektifan penyelenggaraan pelatihan ini.

\section{HASIL DAN PEMBAHASAN HASIL}

Pertemuan pertama secara synchronous pada tanggal 5 September 2020 dengan agenda pembukaan secara resmi oleh Program Studi S2 Pendidikan Matematika, MGMP Matematika SMA Kab Lebak dan Matematika Nusantara Wilayah Banten. Selanjutnya diadakan pelatihan Scilab. Berikut tangkap layar dari rekaman pada pertemuan ke-1 tersebut. Selain itu, disampaikan juga terkait aplikasi Edmodo yang digunakan dalam asynchronous. 

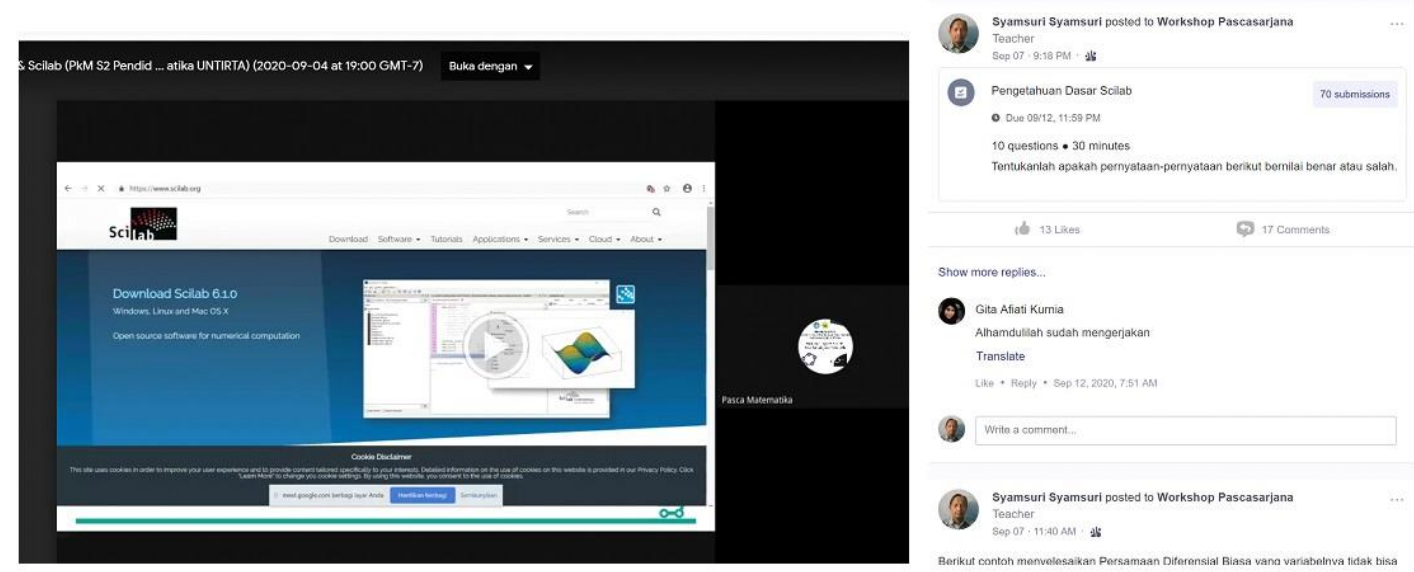

Gambar 1. Pertemuan Ke-1 secara synchronous materi Scilab

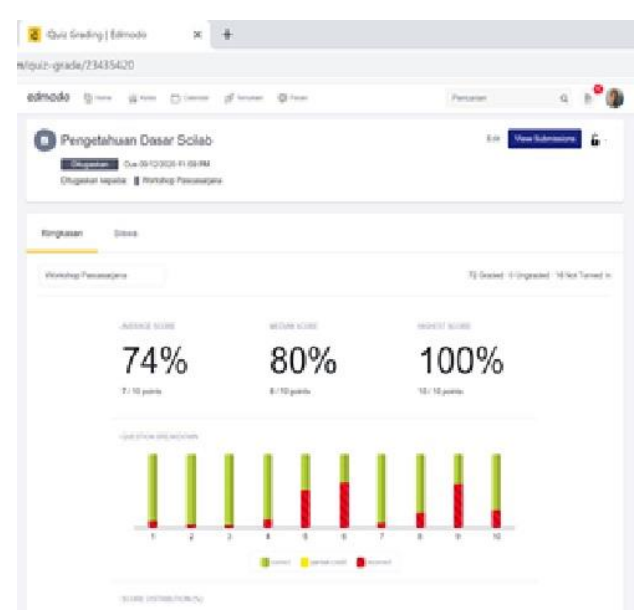

Gambar 2. Hasil uji pengetahuan dasar peserta terkait software Scilab pada Pertemuan ke-1.

Pertemuan kedua secara synchronous pada tanggal 19 September 2020 dengan agenda pelatihan Scilab tentang Polinomial Taylor : Belajar Mudah Fungsi”. Berikut tangkap layar dari rekaman pada pertemuan ke-2 tersebut.

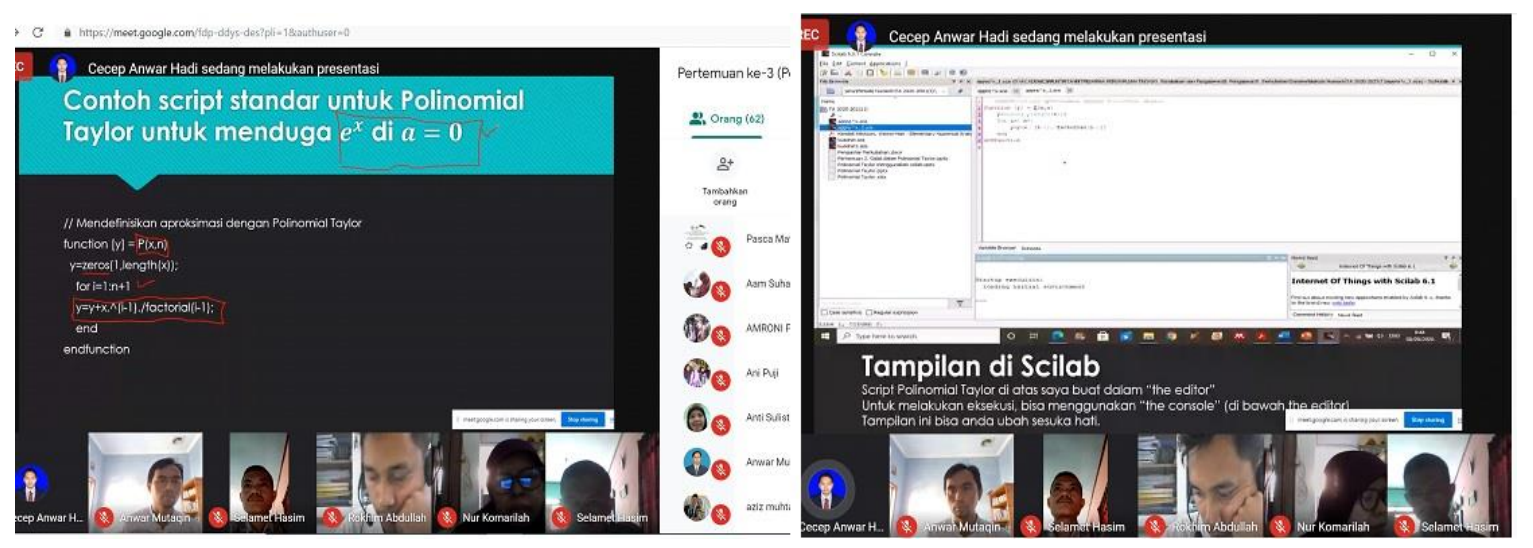

Gambar 3. Pertemuan Ke-2 secara synchronous materi Scilab 
Syamsuri, \& Nindiasari H. (2021). Penguatan konsep matematis bagi guru matematika melalui pelatihan software Scilab secara daring. ABSYARA: Jurnal Pengabdian Pada Masyarakat, 2(1), 8-14. doi:10.29408/ab.v2i1.3190

\section{PEMBAHASAN}

Pelatihan dalam memanfaatkan Scilab dalam pembelajaran matematika ini diharapkan mengurangi kesulitan guru dalam menggunakan software tersebut. Terdapat kendala yang muncul pada saat software Scilab ini, yaitu: 1) tidak terbiasanya/terlatih guru menggunakan software pembelajaran, akan mengakibatkan proses belajar tidak sesuai harapan karena pengajar tidak memahami betul karakteristik software pembelajaran yang digunakan, 2) guru belum memiliki software Scilab ini di komputernya masing-masing sehingga diperlukan waktu untuk proses instalasi, dan 3) beberapa konsep matematika belum secara penuh dikuasai guru.

Guru matematika pun sudah menyadari bahwa beberapa topik dalam matematika bisa memanfaatkan software matematika. Hal ini berguna agar konsep matematis yang sulit dijelaskan kepada siswa dapat disampaikan secara tuntas. Sebagai contoh, guru kesulitan menjelaskan konsep limit, turunan, dan integral secara mendasar karena kesulitan dalam menggambar grafik. Guru memang bisa menggambar grafik tetapi memerlukan waktu yang relatif lama. Padahal yang akan ditanamkan guru kepada siswa bukan menggambar grafiknya, tetapi konsep limit, turunan, dan integral.

Software Scilab bagi guru-guru matematika masih tergolong asing dan belum pernah digunakan. Hal ini dikarenakan karena materi matematika di sekolah menengah masih relatif sederhana dan dapat menggunakan software pembelajaran matematika lainnya yang lebih fungsional, seperti Geogebra. Adapun Scilab oleh Randjawali \& Riupassa (2019) diterapkan pada materi kalkulus di perguruan tinggi. Walupun demikian, Supriyadi (2020) berhasil menggunakan Scilab ini pada siswa SMK dalam operasi matematika dasar dan dasar-dasar pemrograman komputer. Hal tersebut tentunya memberikan arahan bahwa Scilab layak digunakan bagi guru-guru matematika untuk mengetahui aplikasi dari konsep matematika yang dipelajari di sekolah.

Setelah pertemuan terakhir, para peserta diminta untuk mengisi kuesioner secara daring terkait pelaksanaan pelatihan yang telah diikuti. Namun dari 68 peserta yang mengikuti ternyata hanya 36 peserta yang melakukan pengisian kuesioner. Berikut ringkasan terkait keterampilan dan pengetahuan peserta baik di awal maupun setelah mengikuti pelatihan.

Tabel 1. Kontribusi pelatihan ini pada keterampilan/pengetahuan guru

\begin{tabular}{cc}
\hline Kontribusi pelatihan & Banyaknya Guru \\
\hline Cukup & 10 \\
Luar biasa & 6 \\
Memuaskan & 9 \\
Rendah & 3 \\
Sangat baik & 8 \\
\hline Total & $\mathbf{3 6}$ \\
\hline
\end{tabular}

Berdasarkan Tabel 1, terlihat guru matematika mengapresiasi pelatihan software Scilab ini. Diharapkan adanya bahan ajar yang memadukan konsep matematis di sekolah yang bisa diajarkan melalui software Scilab. Dari pelatihan ini, terlihat bahwa pelatihan daring bisa meningkatkan keterampilan dan pengetahuan peserta, seperti pelatihan yang telah dilakukan 
Syamsuri, \& Nindiasari H. (2021). Penguatan konsep matematis bagi guru matematika melalui pelatihan software Scilab secara daring. ABSYARA: Jurnal Pengabdian Pada Masyarakat, 2(1), 8-14. doi:10.29408/ab.v2i1.3190

oleh Widarma \& Saleh (2020). Dengan demikian perlu adanya keberlanjutan dari pelatihan daring ini.

\section{SIMPULAN}

Kegiatan pengabdian masyarakat yang dilakukan tim dosen Program Studi Magister Pendidikan Matematika Universitas Sultan Ageng Tirtayasa bertema pelatihan Scilab untuk pembelajaran matematika ini dapat mengembangkan pengetahuan dan keterampilan guru matematika terkait software pembelajaran matematika. Hal tersebut dapat terlihat bahwa Sebagian besar peserta memberikan penilaian baik dalam masa pelatihan dan mendapatkan kontribusi yang memadai terkait software Scilab. Diharapkan bahwa kegiatan pengabdian seperti ini dapat dilakukan dengan cara berkelanjutan pada masa-masa yang akan datang.

\section{UCAPAN TERIMAKASIH}

Ucapan terima kasih disampaikan kepada Pascasarjana dan LPPM Universitas Sultan Ageng Tirtayasa yang telah menyetujui pelatihan software Scilab ini, serta para guru yang tergabung dalam wadah MGMP Matematika SMA Kabupaten Lebak dan Matematika Nusantara Wilayah Banten.

\section{PERNYATAAN PENULIS}

Artikel pengabdian kepada masyarakat berjudul "Penguatan Konsep Matematis Bagi Guru Matematika Melalui Pelatihan Software Scilab Secara Daring” ini belum pernah dipublikasikan dalam jurnal ilmiah manapun.

\section{DAFTAR PUSTAKA}

Dirgantoro, K. P. S. (2018). Kompetensi guru matematika dalam mengembangkan kompetensi matematis siswa. Scholaria: Jurnal Pendidikan Dan Kebudayaan, 8(2), 157-166.

Mendiknas. (2007). Permendiknas Nomor 16 Tahun 2007: Standar Kualifikasi Akademik dan Kompetensi Guru. Jakarta: Kementerian Pendidikan Nasional.

Nasution, S. H. (2018). Pentingnya literasi teknologi bagi mahasiswa calon guru matematika. Jurnal Kajian Pembelajaran Matematika, 2(1), 14-18.

Padmanthara, S. (2012). Pembelajaran berbantuan komputer (PBK) dan manfaat sebagai media pembelajaran. Tekno, 1(1), 1-8. Retrieved from http://journal.um.ac.id/index.php/tekno/article/viewFile/3234/3918

Randjawali, E., \& Riupassa, R. D. (2019). Simulated analysis of image formation for concave mirror with Scilab by using the concept of calculus. Journal of Physics: Conference Series, 1204(1). https://doi.org/10.1088/1742-6596/1204/1/012067

Ravendran, D. R., \& Daud, M. Y. (2020). Faktor-faktor yang mempengaruhi guru matematik sekolah rendah dalam mengintegrasikan penggunaan teknologi dalam PdPc. Jurnal Dunia Pendidikan, 1(3), 24-33.

Sugilar, H. (2020, March). Multimedia matematika di era digital. In Prosiding-Seminar Nasional Teknik Elektro UIN Sunan Gunung Djati Bandung (pp. 442-451). 
Supriyadi, E. (2020). Penggunaan Scilab untuk memperkenalkan pada siswa SMK tentang dasar matematika dalam pemrograman komputer. GAUSS: Jurnal Pendidikan Matematika, 3(2), 11-21.

Sutisna, U., Elkarimah, M. F., \& Asma, F. R. (2020). Pengembangan kompetensi profesional guru PAI melalui pemanfaatan teknologi informasi. ABSYARA: Jurnal Pengabdian Pada Masyarakat, 1(2), 9-14. DOI: 10.29408/ab.v1i2.2629

Widarma, A., \& Saleh, K. (2020). Pelatihan pembuatan media pembelajaran menggunakan Power Point, Wonder Share Quiz Creator dan Edmodo di SMK Apipsu Medan. Jurnal Anadara Pengabdian Kepada Masyarakat, 2(1), 55-60. 